\title{
Desempenho Exportador Brasileiro Recente e Taxa de Câmbio Real: uma Análise Setorial*
}

\author{
Sérgio Kannebley Júnior ${ }^{* *}$
}

Sumário: 1. Introdução; 2. Análise descritiva do desempenho exportador; 3. Análise econométrica; 4. Considerações finais.

Palavras-chave: exportações; taxa de câmbio real; testes de raiz unitária; causalidade de Granger.

Códigos JEL: F00 e C12.

Este artigo investiga a relação entre medidas alternativas de taxa de câmbio real e a evolução do quantum exportado para 13 setores exportadores nacionais, no período de 1985 a 1998. É possível concluir, por meio de análise descritiva e econométrica, que não existe uma relação de longo prazo estável entre a evolução do nível da taxa de câmbio real e o quantum exportado para a maioria dos setores analisados. Argumenta-se, entretanto, que a manutenção de um nível de taxa real de câmbio capaz de preservar a rentabilidade e/ou competitividade dos setores exportadores é condição necessária, porém não suficiente, para a expansão das exportações ao longo do tempo.

This paper investigates the relationship between alternative measures of real exchange rate and the exported quantum evolution for 13 Brazilian exporting sectors from 1985 to 1999. The descriptive and econometric analyses showed that a long-run relationship between the real exchange rate evolution and the exported quantum does not exist for most of the exporting sectors analyzed. Nonetheless, an adequate level of real exchange rate to maintain the profitability and/or the competitiveness of the exporting sectors is a necessary, though not sufficient condition for the expansion of exports over time.

\footnotetext{
${ }^{*}$ Artigo recebido em dez. 2000 e aprovado em abr. 2002. Agradecimentos a Ricardo Markwald e Henry Pourchet, pela cessão dos índices produzidos pela Funcex, e a Pierre Perron e Serena $\mathrm{Ng}$, pela cessão das rotinas dos testes de raiz unitária com quebra estrutural. Qualquer erro ou omissão é de exclusiva responsabilidade do autor.

${ }^{* *}$ Professor da FEA/USP, campus de Ribeirão Preto.
} 


\section{Introdução ${ }^{1}$}

Após a mudança do regime cambial realizada em janeiro de 1999 e a conseqüente desvalorização da taxa de câmbio ao longo deste mesmo ano, esperava-se uma reversão sensível dos resultados deficitários da balança comercial, não apenas em razão da redução do valor das importações, mas também devido a uma expectativa de aumento sensível do valor total exportado pelo Brasil.

Ainda que a taxa de câmbio nominal em relação ao dólar tenha-se desvalorizado, em média, de 1998 para 1999, 56,4\%, provocando uma correspondente desvalorização da taxa real de câmbio efetiva das exportações em torno de $32,8 \%$, o valor exportado neste mesmo período decresceu 6,1\%. Este resultado deveu-se, em grande parte, à queda de $12,8 \%$ dos preços das exportações. Ainda assim, o aumento de $7,7 \%$ do quantum exportado demonstrou-se extremamente tímido em face de uma desvalorização da taxa real de câmbio tão pronunciada. Este último fato fez com que se questionasse o motivo desta lenta resposta das exportações à desvalorização cambial.

Admitindo que, em média, os setores exportadores nacionais possam ser considerados como tomadores de preços no mercado internacional, ou então praticantes de um baixo grau de repasse da taxa de câmbio ao preço de exportação, isto significa dizer que a recente desvalorização cambial produziu, predominantemente, uma alteração positiva da rentabilidade da atividade exportadora, não resultando necessariamente em alterações sensíveis na competitividade destes setores com relação aos seus concorrentes internacionais. Assim, para que fosse observado um aumento substancial das exportações no curto prazo, ou, ainda, a fim de que se notasse um aumento na taxa de crescimento das exportações, seria necessária a verificação de uma relação de longo prazo entre o quantum exportado e a rentabilidade da atividade exportadora do setor, combinada à presença de um alto coeficiente de velocidade de resposta aos desvios dessa relação.

Dada a relação teórica entre o desempenho exportador de um país e a taxa real de câmbio, neste artigo, por meio de uma análise descritiva e econométrica, procurar-se-á investigar, para o período de 1985 a 1998, a validade dessa relação de longo prazo para 13 setores exportadores analisados, correspondentes a 56,07\% do valor total das exportações brasileiras. São eles: extrativa mineral $(6,94 \%)$, siderurgia $(7,38 \%)$, metais não-ferrosos $(4,13 \%)$, máquinas e tratores $(4,93 \%)$, material elétrico $(2,72 \%)$, equipamentos eletrônicos $(1,92 \%)$, veículos automotores $(4,61 \%)$, peças e outros veículos $(8,26 \%)$, madeira e mobiliário $(2,90 \%)$, celu-

\footnotetext{
${ }^{1}$ Os números entre parênteses correspondem à participação percentual média dos setores no total das exportações no período 1996-98.
} 
lose, papel e gráfica (3,94\%), elementos químicos $(2,10 \%)$, têxtil $(1,99 \%)$, calçados $(4,25 \%)$.

$\mathrm{O}$ artigo é composto de três seções, além desta introdução. Na seção 2, com o auxílio das informações para o agregado das exportações, será realizada uma descrição quantitativa do desempenho exportador no período de 1985 a 1999 e uma análise deste desempenho com base em indicadores de rentabilidade e competitividade das exportações. Na seção 3 será conduzida uma análise econométrica para o período de 1985 a 1998, em que serão investigadas as características temporais das séries de índices de quantum setoriais e realizados testes de causalidade de Granger entre os índices de quantum setoriais e medidas alternativas de taxa real de câmbio, além de variáveis representativas da demanda e da produção física doméstica. Na seção 4 são tecidas considerações finais sobre os resultados obtidos e estabelecidas relações com as conduções de políticas econômicas.

\section{Análise Descritiva do Desempenho Exportador}

O caráter interdependente das políticas monetária, fiscal e cambial, em conjunção com a instabilidade macroeconômica vivida nos anos 1980 e início dos anos 1990, suscitou por diversas vezes alterações da política cambial. Essas alterações estavam associadas, de modo mais ou menos direto, ao objetivo maior de estabilização da inflação e manutenção do equilíbrio externo da economia, compreendendo mudanças de regimes cambiais e regras de condução e administração das taxas de câmbio e dos mercados cambiais. ${ }^{2}$

A partir de 1995, atingida a estabilização dos preços com a implementação do Plano Real, foi introduzido o regime de bandas cambiais com o objetivo de incrementar a credibilidade da política cambial, por meio da adoção de medidas que implicavam maior estabilidade da taxa de câmbio real e o padrão de variação da taxa nominal de câmbio. Em janeiro de 1999 a manutenção deste regime tornou-se insustentável, levando o governo a adotar um regime de taxas de câmbio flexíveis, produzindo uma sensível desvalorização das taxas de câmbio nominal e real.

Antes de concentrar a análise sobre a relação entre a taxa real de câmbio e o desempenho exportador dos setores, é interessante apresentar um quadro geral da evolução das exportações brasileiras ao longo dos anos de 1980 e 1990. A tabela 1 apresenta a composição relativa da pauta de exportações, por classe de produtos (básicos, semimanufaturados e manufaturados) e de acordo com as categorias de

\footnotetext{
${ }^{2}$ Informações adicionais sobre a condução da política cambial a partir de 1980 podem ser obtidas em Zini (1993), Horta et al. (1991), Holland (1996) e Bonomo \& Terra (1999).
} 
uso (bens de capital, intermediários, bens de consumo duráveis, de consumo nãoduráveis e combustíveis). Como é possível notar, a pauta de exportações altera-se nos anos 1990 com relação à composição relativa dos anos 1980. Amplia-se a participação dos produtos manufaturados e semimanufaturados em contraposição à queda da participação dos produtos básicos, bem como aumenta a participação dos bens de capital e decresce a exportação de combustíveis, além de oscilar a exportação de bens de consumo duráveis.

Tabela 1

Participação relativa nas exportações

\begin{tabular}{lrrrrrrrr}
\hline & \multicolumn{2}{c}{1986} & \multicolumn{2}{c}{1990} & \multicolumn{2}{c}{1994} & \multicolumn{2}{c}{1998} \\
\hline & Valor & \% Total & Valor & \% Total & Valor & \% Total & Valor & \% Total \\
Total & 22.176 & 100,00 & 30.866 & 100,00 & 42.910 & 100,00 & 50.463 & 100,00 \\
Básicos & 7.280 & 32,83 & 8.747 & 28,34 & 11.058 & 25,77 & 12.970 & 25,70 \\
Semimanufaturados & 2.492 & 11,24 & 5.108 & 16,55 & 6.893 & 16,06 & 8.127 & 16,10 \\
Manufaturados & 12.404 & 55,93 & 17.011 & 55,11 & 24.959 & 58,17 & 29.366 & 58,19 \\
Bens de capital & 1.373 & 6,19 & 2.145 & 6,95 & 3.946 & 9,20 & 5.799 & 11,49 \\
Intermediários & 14.479 & 65,29 & 21.714 & 70,35 & 29.372 & 68,45 & 33.245 & 65,88 \\
Duráveis & 1.212 & 5,47 & 1.491 & 4,83 & 1.983 & 4,62 & 2.837 & 5,62 \\
Não-duráveis & 4.545 & 20,50 & 5.379 & 17,43 & 7.373 & 17,18 & 8.855 & 17,55 \\
Combustíveis & 739 & 3,33 & 685 & 2,22 & 871 & 2,03 & 384 & 0,76 \\
\hline Fonte: Funcex & & & & & & & &
\end{tabular}

Valor em US\$ milhões

Os dados do Ministério do Desenvolvimento, Indústria e Comércio revelam, na tabela 2, que as exportações brasileiras vêm ampliando, ao longo do tempo, sua participação no mercado latino-americano e em países em desenvolvimento em geral. Em contrapartida a este movimento expansionista é notada uma relativa estagnação das exportações brasileiras nos mercados compostos por países desenvolvidos, ou industrializados. Nonnenberg (1998) destaca que os principais fatores responsáveis por esta mudança na orientação do destino das exportações são os diversos processos de integração regional provocados por alterações recentes na estrutura tarifária, como no caso do Nafta, e a evolução comercial intrabloco, nos casos da CEE e do Mercosul.

Dessa forma, é possível observar que, ao longo dos anos 1990, ocorreu um processo de reestruturação da pauta exportadora, em direção ao aumento da participação de bens manufaturados e semimanufaturados, intensificando uma tendência prevalecente desde os anos 1970, bem como uma reorientação dos mercados-destino de nossas exportações, aumentando a importância dos fatores regionais e institucionais na definição dos principais demandantes de produtos nacionais. 
Tabela 2

Mercados-destino das exportações brasileiras

\begin{tabular}{|c|c|c|c|}
\hline Mercado & 1990 & 1993 & 1998 \\
\hline Países industrializados & 21.383 & 21.578 & 26.687 \\
\hline$\Delta \mathrm{EUA}$ & 7.734 & 8.026 & 9.741 \\
\hline ム Japão & 2.349 & 2.313 & 2.202 \\
\hline \ Europa & 10.547 & 10.556 & 14.744 \\
\hline \multicolumn{4}{|l|}{ Países em desenvolvimento } \\
\hline \ África & 765 & 871 & 1.651 \\
\hline \ Ásia & 2.921 & 3.853 & 3.411 \\
\hline China & 382 & 779 & 905 \\
\hline Coréia do Sul & 543 & 538 & 467 \\
\hline \ Europa & 927 & 835 & 1.163 \\
\hline$\Delta$ Oriente médio & 1.307 & 1.457 & 1.611 \\
\hline \ América Latina e Caribe & 3.636 & 9.773 & 13.324 \\
\hline Argentina & 645 & 3.661 & 6.747 \\
\hline Outros países & 476 & 415 & 3.273 \\
\hline Total & 31.415 & 38.782 & 51.120 \\
\hline
\end{tabular}

O gráfico da figura 1 apresenta índices de preços PTOTAL, quantum (QTOTAL) e o relativo de valor (VTOTAL) para o agregado das exportações brasileiras no período de 1974 a 1999.

Figura 1

Índices de preços, quantum, e relativo do valor agregado das exportações

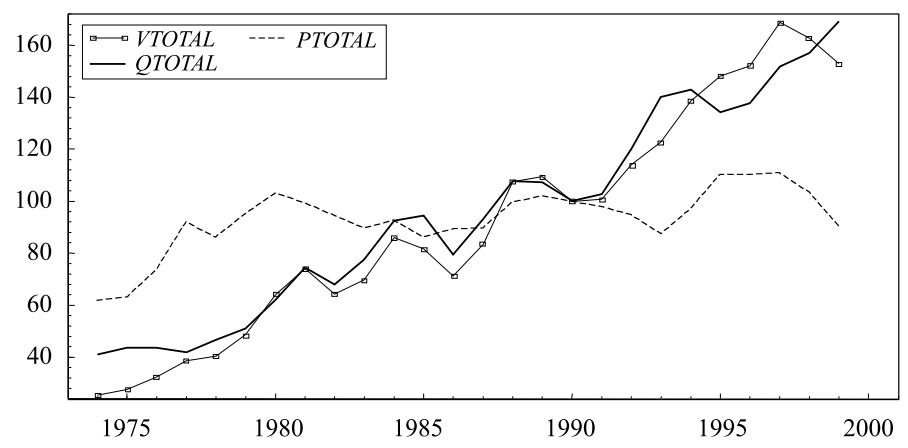


É possível observar que o índice de preços para o agregado das exportações brasileiras apresenta um comportamento relativamente mais estável do que os índices de relativo de valor e de quantum exportado. É clara a relação entre a expansão do valor exportado e o aumento do volume exportado. Quanto aos 13 setores selecionados, segundo os dados apresentados nas tabelas A.1 e A.2 no anexo a este artigo, esta relação positiva entre a evolução do valor e o volume exportado somente não é verificada de modo claro para os setores de siderurgia, veículos, madeira e mobiliário e calçados.

Para o período de 1985 a 1999 foram obtidos índices de rentabilidade, propostos por Pinheiro \& Horta (1992), de acordo com a seguinte expressão:

$$
R_{k}=\frac{P_{k}}{C_{k}}
$$

em que $R_{k}$ é o índice de rentabilidade das exportações do setor $k$, e $P_{k}$ e $C_{k}$ são os respectivos índices de preços das exportações e custos em dólar para o mesmo setor. A tabela 3 apresenta os índices de rentabilidade para o agregado das exportações e para os demais 13 setores selecionados. Conforme pode ser observado na figura 2, a rentabilidade para o agregado das exportações mantém-se elevada até o ano de 1988. Em 1989 o índice apresenta forte queda em razão do atraso cambial ocasionado pela aceleração da inflação nesse ano. É importante notar que tal comportamento não encontra contrapartida na evolução do total quantum exportado. A recuperação do índice de rentabilidade se dá com a correção cambial efetuada na introdução do Plano Collor I e é mantida em um nível ligeiramente abaixo em 1992.

Figura 2

Índice de rentabilidade do agregado das exportações brasileiras

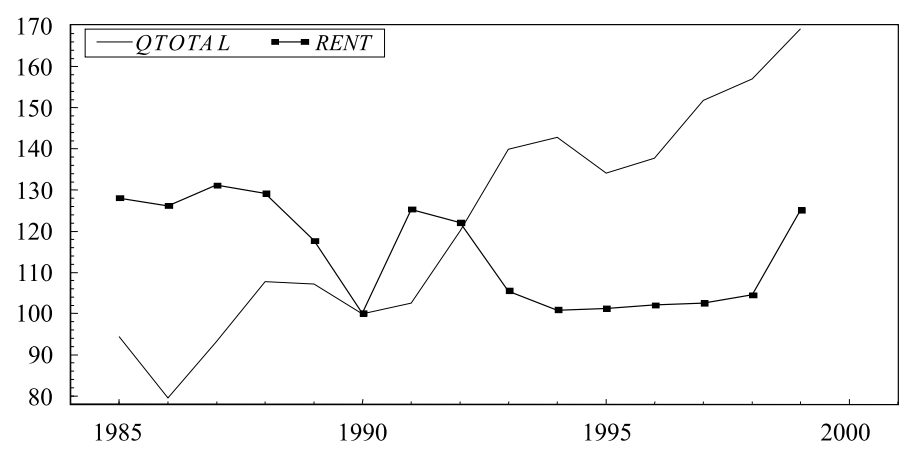


O ano de 1993 é novamente de aceleração da inflação, reproduzindo o fenômeno de queda do índice ocorrido em 1989. A valorização cambial permitida na implementação do Plano Real deprimiu ainda mais este índice em 1994, recuperando-se lentamente a partir desse ano até 1998. No ano de 1999, com a desvalorização cambial ocorrida em janeiro, o índice recupera-se, atingindo um nível comparável aos anos de 1991/92. As discrepâncias com relação a este comportamento médio ficam por conta das diferentes variabilidades dos índices setoriais, bem como da capacidade de recuperação do índice no período de 1995 a 1997.

Tabela 3

Índices de rentabilidade: 1985-99

\begin{tabular}{lrrrrrr}
\hline & $1985-8$ & 1989 & 1990 & 1991 & 1992 & 1993 \\
\hline Total & 128,7 & 117,7 & 100,0 & 125,3 & 122,1 & 105,5 \\
Extrativa mineral & 116,5 & 109,9 & 100,0 & 133,0 & 121,9 & 100,7 \\
Siderurgia & 113,5 & 128,0 & 100,0 & 127,2 & 108,7 & 102,9 \\
Metais não-ferrosos & 116,0 & 140,6 & 100,0 & 104,8 & 102,5 & 92,8 \\
Máquinas e tratores & 128,5 & 105,0 & 100,0 & 121,9 & 122,5 & 105,1 \\
Material elétrico & 118,9 & 111,3 & 100,0 & 131,4 & 129,6 & 114,4 \\
Equipamentos eletrônicos & 118,5 & 115,7 & 100,0 & 129,9 & 135,8 & 132,9 \\
Veículos automotores & 136,7 & 122,2 & 100,0 & 139,6 & 137,6 & 120,4 \\
Peças e outros veículos & 149,5 & 107,7 & 100,0 & 132,8 & 128,6 & 92,9 \\
Madeira e mobiliário & 150,1 & 109,5 & 100,0 & 129,7 & 132,5 & 120,6 \\
Celulose, papel e gráfica & 134,3 & 127,7 & 100,0 & 107,4 & 100,6 & 74,0 \\
Elementos químicos & 119,3 & 129,0 & 100,0 & 114,2 & 117,1 & 104,5 \\
Têxtil & 150,9 & 105,2 & 100,0 & 132,5 & 128,1 & 108,4 \\
Calçados & 121,9 & 112,1 & 100,0 & 143,4 & 131,8 & 110,0 \\
\hline
\end{tabular}

\begin{tabular}{lrrrrrr}
\hline & 1994 & 1995 & 1996 & 1997 & 1998 & 1999 \\
\hline Total & 100,8 & 101,3 & 102,1 & 102,6 & 104,6 & 123,7 \\
Extrativa mineral & 86,3 & 80,4 & 85,2 & 85,7 & 91,4 & 112,2 \\
Siderurgia & 95,3 & 101,3 & 97,0 & 99,3 & 100,7 & 103,7 \\
Metais não-ferrosos & 91,6 & 102,8 & 98,5 & 96,9 & 93,3 & 112,6 \\
Máquinas e tratores & 100,7 & 91,2 & 93,3 & 97,1 & 101,7 & 130,0 \\
Material elétrico & 109,6 & 105,4 & 117,7 & 119,2 & 126,6 & 156,3 \\
Equipamentos eletrônicos & 150,9 & 134,1 & 140,0 & 138,2 & 150,1 & 161,0 \\
Veículos automotores & 112,9 & 107,8 & 115,3 & 118,7 & 131,7 & 146,6 \\
Peças e outros veículos & 90,2 & 87,8 & 93,9 & 92,9 & 100,0 & 124,5 \\
Madeira e mobiliário & 103,6 & 100,1 & 101,8 & 103,4 & 98,8 & 124,1 \\
Celulose, papel e gráfica & 83,1 & 115,2 & 81,6 & 78,0 & 79,2 & 101,8 \\
Elementos químicos & 85,8 & 86,0 & 91,9 & 88,5 & 86,8 & 103,4 \\
Têxtil & 107,5 & 108,7 & 115,4 & 118,1 & 117,5 & 132,6 \\
Calçados & 106,2 & 99,5 & 103,3 & 101,1 & 98,3 & 118,1 \\
\hline Fonte: Funcex; cálculos do autor & & & & &
\end{tabular}

Fonte: Funcex; cálculos do autor.

A tabela 4 apresenta os coeficientes de exportação setoriais e para o total da indústria, calculados por Haguenauer et al. (1998) e atualizados segundo informações da Funcex. Para a maioria dos setores considerados na análise, os anos de 1991 e 1992 configuram-se como períodos de elevação da média dos coeficientes de exportação setoriais com relação àquela verificada no período de 1985 a 1990. Também para a maioria dos setores industriais verificou-se uma inflexão 
para baixo dos coeficientes de exportação nos anos de 1994 e 1995, biênio em que o aumento da demanda doméstica foi impulsionado pelos ganhos reais de renda promovidos pela estabilização econômica, e houve uma forte apreciação cambial logo após a implementação do Plano Real. No entanto, ao longo dos anos de 1996 a 1998, ainda que a taxa real de câmbio estivesse apreciada, notou-se um movimento de recuperação dos coeficientes de exportação em direção à média do início da década, que somente não é acompanhado pelos setores de extrativa mineral e siderurgia. Ou seja, o que estes indicadores evidenciam é uma relativa inflexibilidade dos coeficientes de exportação à mudança de média ocorrida no início dos anos 1990 e o prevalecimento, para os anos 1990, de uma média para os coeficientes de exportação setoriais mais elevada do que aquela verificada no período de 1985 a $1990 .^{3}$

Tabela 4

Coeficientes de exportação: 1985-98

\begin{tabular}{lrrrrrrr}
\hline & 1985 & 1986 & 1987 & 1988 & 1989 & 1990 & 1991 \\
\hline Siderurgia & 16,1 & 13,6 & 13,3 & 22,5 & 20,5 & 16,3 & 26,5 \\
Metais não-ferrosos & 12,1 & 13,0 & 18,4 & 31,0 & 22,5 & 20,6 & 30,4 \\
Máquinas e tratores & 7,5 & 5,8 & 5,4 & 6,3 & 5,0 & 4,0 & 7,0 \\
Material elétrico & 7,0 & 6,6 & 7,8 & 8,3 & 8,7 & 6,3 & 12,4 \\
Equipamentos eletrônicos & 11,1 & 11,2 & 11,5 & 10,2 & 7,8 & 4,6 & 8,0 \\
Veículos automotores & 14,1 & 10,3 & 19,6 & 14,9 & 12,8 & 6,4 & 7,5 \\
Peças e outros veículos & 21,2 & 16,1 & 21,1 & 15,7 & 15,1 & 12,3 & 18,6 \\
Madeira e mobiliário & 7,8 & 6,5 & 6,5 & 8,4 & 3,6 & 3,1 & 4,9 \\
Celulose, papel e gráfica & 7,8 & 8,9 & 8,6 & 11,2 & 8,2 & 7,2 & 9,4 \\
Elementos químicos & 6.4 & 7.6 & 5.8 & 7.7 & 9.0 & 7.4 & 9.7 \\
Têxtil & 8,3 & 6,1 & 9,3 & 8,0 & 7,5 & 6,7 & 10,8 \\
Calçados & 32,0 & 26,8 & 35,2 & 37,2 & 26,7 & 29,6 & 46,5 \\
\hline & & & & & & & \\
\hline & 1992 & 1993 & 1994 & 1995 & 1996 & 1997 & 1998 \\
\hline Siderurgia & 21,8 & 19,5 & 15,6 & 14,8 & 14,7 & 13,0 & 13,8 \\
Metais não-ferrosos & 37,6 & 34,3 & 31,6 & 31,3 & 30,8 & 29,7 & 25,9 \\
Máquinas e tratores & 9,0 & 9,0 & 8,88 & 8,20 & 10,0 & 11,0 & 11,3 \\
Material elétrico & 17,6 & 19,3 & 16,7 & 15,3 & 15,2 & 16,9 & 19,9 \\
Equipamentos eletrônicos & 12,1 & 10,3 & 8,3 & 6,6 & 8,1 & 11,7 & 16,9 \\
Veículos automotores & 13,2 & 9,4 & 7,7 & 4,8 & 6,1 & 10,9 & 16,6 \\
Peças e outros veículos & 20,3 & 17,7 & 15,7 & 13,1 & 14,8 & 16,6 & 23,0 \\
Madeira e mobiliário & 7,5 & 8,7 & 8,8 & 7,4 & 7,2 & 8,2 & 8,7 \\
Celulose, papel e gráfica & 10,5 & 9,9 & 11,1 & 12,3 & 10,0 & 11,2 & 12,0 \\
Elementos químicos & 11.3 & 11.0 & 9.0 & 11.0 & 13,2 & 13,5 & 15,0 \\
Têxtil & 12,4 & 10,2 & 9,4 & 9,2 & 9,6 & 10,9 & 11,1 \\
Calçados & 54,1 & 55,9 & 45,4 & 46,5 & 56.5 & 63.0 & 69.7 \\
\hline Fonte: Hagur & & & &
\end{tabular}

Fonte: Haguenauer et al. (1998); atualização Funcex.

\footnotetext{
${ }^{3} \mathrm{O}$ comportamento dos coeficientes de exportação apresentados aqui assemelha-se, em linhas gerais, ao dos coeficientes de exportação calculados por Moreira (1999).
} 
Na tabela 5 são apresentados os indicadores de custo unitário da mão-de-obra em dólar (ULC), da relação produto por pessoal ocupado (PRODT) para a indústria e as taxas de câmbio real com relação ao dólar (TCRD) e efetiva (TCRE) para as exportações. Nessa tabela demonstra-se que as exportações brasileiras tornaram-se menos competitivas em relação aos demais parceiros comerciais por dois motivos: a valorização da taxa de câmbio real e o aumento do salário real. Enquanto ao longo dos anos 1980 a produtividade do trabalho permaneceu relativamente estagnada, nos anos 1990 seu crescimento é notório. É importante notar que este forte aumento da produtividade do trabalho ao longo dos anos 1990 contrabalançou o aumento do salário em dólar, evitando um crescimento ainda maior do custo unitário da mão-de-obra no período. ${ }^{4}$ Com relação às taxas reais de câmbio, seus movimentos assemelham-se aos do índice agregado de rentabilidade das exportações, com diferenças resultantes das relações triangulares entre as outras moedas internacionais e o dólar.

Tabela 5

Indicadores de competitividade

\begin{tabular}{ccccc}
\hline Ano & ULC & PRODT & TCRD & TCRE \\
\hline 1985 & 46,5 & 102,4 & 190,0 & 146,6 \\
1986 & 55,0 & 102,3 & 169,4 & 153,0 \\
1987 & 60,5 & 102,0 & 163,4 & 159,0 \\
1988 & 69,9 & 103,0 & 145,0 & 143,5 \\
1989 & 100,7 & 103,9 & 125,1 & 118,5 \\
1990 & 100,0 & 100,0 & 100,0 & 100,0 \\
1991 & 84,2 & 108,4 & 121,0 & 116,3 \\
1992 & 86,9 & 113,0 & 129,1 & 127,8 \\
1993 & 92,7 & 123,8 & 119,2 & 114,0 \\
1994 & 96,1 & 136,2 & 102,1 & 98,3 \\
1995 & 113,9 & 141,4 & 91,5 & 91,7 \\
1996 & 113,8 & 161,9 & 96,5 & 94,4 \\
1997 & 105,1 & 178,5 & 95,7 & 89,5 \\
1998 & 93,8 & 192,4 & 97,0 & 89,6 \\
1999 & 56,4 & 206,3 & 131,4 & 119,1 \\
\hline Fontes: Bonneli \& Fonseca (1998), Ipeadata e cálculos do autor.
\end{tabular}

Assim, o que se pode concluir por meio desta análise descritiva é que ainda que a política cambial tenha sido conduzida de modo extremamente instável e tenha contribuído para o declínio da rentabilidade e competitividade das exportações brasileiras, como informam os indicadores de rentabilidade, de custo unitário do trabalho e de taxa de câmbio real em dólar e efetiva das exportações, o valor das exportações no agregado cresceu, ao longo de 1985 a 1998, a uma taxa média

\footnotetext{
${ }^{4}$ Segundo a análise de Bonneli \& Fonseca (1998), o aumento do custo unitário da mão-deobra deveu-se principalmente ao aumento do salário real ocorrido nos primeiros anos Plano Real e secundariamente à valorização do câmbio real.
} 
de aproximadamente 5,1\%, obtendo um crescimento acumulado de $101,6 \% .^{5} \mathrm{O}$ índice de preços agregado apresentou uma elevação média no período de 1,3\%, e acumulada em torno de 19,8\%, enquanto o índice de quantum agregado apresentou um aumento médio de 3,7\% e acumulado em torno de 66,3\%. De 1990 a 1998, o valor das exportações apresentou um crescimento acumulado de $62,8 \%$, e o quantum exportado no mesmo período cresceu $57 \%$, enquanto os preços cresceram somente 3,6\%, com respectivas taxas médias de crescimento de 5,6\%, 5,1\% e 0,4\%. Ou seja, tanto os valores acumulados quanto os valores médios demonstram que o principal componente responsável pelo crescimento do valor das exportações foi o aumento do volume exportado, sendo grande parte deste aumento verificada ao longo dos anos 1990. Concomitantemente, houve neste período uma alteração no destino das exportações, com a relativa estagnação dos mercados industrializados e o aumento da participação dos países subdesenvolvidos, principalmente para o continente latino-americano, acompanhada de valorização da taxa de câmbio real e maior incremento da produtividade do trabalho.

\section{Análise Econométrica}

Esta seção tem o objetivo de analisar, por meio de testes econométricos, os argumentos tecidos anteriormente sobre a influência de outros fatores, como a abertura comercial e os diversos processos de integração regional na determinação da evolução do quantum exportado, bem como as relações de causalidade entre medidas setoriais de taxa real de câmbio e os respectivos índices de quantum exportados. Os dados utilizados são os índices de quantum, preços e custos de exportações setoriais, produzidos pela Funcex (Fundação Centro de Estudos do Comércio Exterior), com metodologia apresentada, respectivamente, em Guimaraes et al. (1997) e Guimarães (1995). Os índices de preços de exportações internacionais foram compostos, em parte, pelos índices de preços de exportações de commodities primárias e metais não-ferrosos, coletados de diversas edições do Monthly Bulletin of Statistics (MBS), das Nações Unidas, e em parte pelos índices de preços das importações norte-americanas, produzidos pelo Bureau of Labor Statistics (BLS). ${ }^{6}$ São utilizados, também, os índices de produção física fornecidos pelo Instituto Brasileiro de Geografia e Estatística (IBGE), apresentados na

\footnotetext{
${ }^{5}$ Segundo Thorstensen (1996), o crescimento médio das exportações nacionais ao longo dos anos 1990, em média, apenas acompanha as médias mundiais, fazendo com que a participação do Brasil nas exportações mundiais decresça de 1,0\%, em média, nos anos 1980, para algo em torno de $0,9 \%$ nos anos 1990 .

${ }^{6}$ A utilização do índice de preços de importações dos EUA tem como inconveniente a ponderação dada pelo intercâmbio comercial norte-americano, além do fato de ser este um mercado
} 
Pesquisa Industrial Mensal, classificados por gênero e por nível 100. O indicador de demanda internacional do setor, para os anos de 1985 a 1990, foi calculado a partir de informações de fontes nacionais como Nonnenberg (1998), Hollanda Filho (1996) e Britto (1993), e para os anos de 1994 a 1998, com base no Comtrade Data Base. O período de análise corresponde ao primeiro trimestre de 1985 ao quarto trimestre de 1998.

\subsection{Testes de raiz unitária}

A análise descritiva realizada acima sugere que as séries dos índices de quantum apresentam características relativamente estáveis de evolução ao longo do tempo. Entretanto, há a possibilidade de existência de quebras estruturais em razão da instabilidade macroeconômica ou do processo de abertura comercial vivenciados pela economia brasileira no período.

A possibilidade de existência de quebras nas séries de índices de quantum, que diminuem o poder dos testes $\mathrm{ADF}$ de raiz unitária, faz com seja necessário a estimação de testes de raiz unitária com a presença de quebras. Sendo assim, foram conduzidos testes de testes de raiz unitária formulados de acordo com Perron \& Vogelsang (1992) e Perron (1993). Foram estimados dois tipos de modelos : a) modelo com outlier aditivo (Aom) e b) modelo com outlier inovacional (Iom). Considerando a possibilidade da presença ou não do termo de tendência nas séries e a ocorrência de uma data de quebra, $T_{b}$, os modelos aditivos são especificados de acordo com os seguintes formas funcionais:

$$
\begin{gathered}
\text { Aom } 0: y_{t}=\mu_{1}+\left(\mu_{2}-\mu_{1}\right) D U_{t}+v_{t} \\
\text { Aom } 1: y_{t}=\mu_{1}+\beta_{1} t+\left(\mu_{2}-\mu_{1}\right) D U_{t}+v_{t} \\
\text { Aom } 2: y_{t}=\mu_{1}+\beta_{1} t+\left(\mu_{2}-\mu_{1}\right) D U_{t}+\left(\beta_{2}-\beta_{1}\right) D T_{t}^{*}+v_{t} \\
\text { Aom } 3: y_{t}=\mu_{1}+\beta_{1} t+\left(\beta_{2}-\beta_{1}\right) D T_{t}^{*}+v_{t}
\end{gathered}
$$

$\overline{\text { de características particulares que não necessariamente refletem as características de formação de }}$ preços a que estão sujeitos os produtos de exportação brasileiros. Contudo, tem como vantagem ser os EUA um dos maiores importadores do mundo, o que não só reduz o efeito da participação relativa do Brasil neste mercado, como também traz informações relevantes sobre os preços das exportações praticados pelos concorrentes internacionais das exportações brasileiras. 
em que $D U_{t}=1$ e 0 de outra forma, $D T_{t^{*}}=t-T_{b}$ se $t>T_{b}$ e 0 de outra forma. O componente $v_{t}$ possui a forma $A(L) v_{t}=B(L) \epsilon_{t}$, em que et $\epsilon_{t} \approx \operatorname{IID}\left(0, \sigma^{2}\right)$, sendo $A(L)$ e $B(L)$ polinômios de defasagem de ordem $p$ e $q$, respectivamente. A hipótese nula de que $y_{t}$ possui uma raiz unitária implica que $A(L)$ pode ser reparametrizado como $(1-L) A^{*}(L)$, em que $A^{*}(L)$ é um polinômio de defasagens com todas raízes fora do círculo unitário. Sob a hipótese alternativa, as raízes características de $A(L)$ encontram-se todas fora do círculo unitário. Dessa forma, o modelo Aom0 representa uma mudança na média do processo para variáveis sem tendência determinista, o modelo Aom 1 representa uma mudança de média para variável com tendência determinista, o modelo Aom2 representa alterações simultâneas de média e tendência, enquanto o modelo Aom3 somente considera mudança na inclinação da tendência.

Em razão da versão Aom3 para o modelo inovador ser de difícil implementação computacional, os modelos inovadores são considerados apenas para os casos 0,1 e 2. Sob a hipótese nula de existência de uma raiz unitária são considerados os seguintes modelos:

$$
\begin{gathered}
\operatorname{Iom} 0: y_{t}=y_{t-1}+b+\varphi(L)\left(\epsilon_{t}+\eta D U\right) \\
\operatorname{Iom} 1: y_{t}=y_{t-1}+b+\varphi(L)\left(\epsilon_{t}+\sigma D\left(T_{b}\right)_{t}\right) \\
\operatorname{Iom} 2: y_{t}=y_{t-1}+b+\varphi(L)\left(\epsilon_{t}+\sigma D\left(T_{b}\right)_{t}+\eta D U\right)
\end{gathered}
$$

em que $D U_{t}=1$ e 0 de outra forma, $D\left(T_{b^{*}}\right)=1$ se $t=T_{b}+1$ e 0 de outra forma. O polinômio $\varphi(L)$ é possivelmente de ordem infinita com $\varphi(0)=1$ e $\varphi(L)=$ $A^{-1}(L) B(L)$. Este modelo especifica a primeira diferença da variável como um processo de média móvel. O subjacente processo sob a hipótese alternativa é :

$$
\begin{gathered}
\operatorname{Iom} 0: y_{t}=\mu+\phi(L)\left(\epsilon_{t}+\Theta D U_{t}\right) \\
\operatorname{Iom} 1: y_{t}=\mu+\beta_{t}+\phi(L)\left(\epsilon_{t}+\Theta D U_{t}\right) \\
\text { Iom } 2: y_{t}=\mu+\beta_{t}+\phi(L)\left(\epsilon_{t}+\gamma D T_{t}^{*}+\Theta D U_{t}\right)
\end{gathered}
$$

em que $\phi(L)=(1-\alpha L)^{-1} A^{-1}(L) B(L)$ e $|\alpha|<1$. 
A diferença entre os modelos outlier aditivo e inovador está na forma como ocorre a transição para a nova média e/ou taxa de crescimento. Enquanto nos modelos aditivos a transição ocorre instantaneamente, nos modelos inovadores a transição é gradual. Neste artigo são estimadas as duas formas funcionais de testes. O método de seleção do parâmetro de defasagem é o $t$-sig, que seleciona o valor $d$, na auto-regressão de ordem $d_{\max }$, cujo último coeficiente é significante. ${ }^{7} \mathrm{O}$ ponto de quebra é escolhido como o valor, sobre todos os pontos de quebra possíveis, que minimiza a estatística $t$ para o teste de $\alpha=1$ na auto-regressão apropriada.

Os resultados dos testes de raiz unitária com break, apresentados na tabela 6 , na qual constam também os pontos de quebra e as estatísticas $t$ associadas às quebras, indicam que, para os setores de extrativa mineral, siderurgia, metais não-ferrosos, peças e outros veículos, material elétrico, madeira e mobiliário, elementos químicos, têxtil e calçados, foi rejeitada a hipótese nula de raiz unitária em nível de significância de $5 \%$ em ao menos uma das formas funcionais estimadas. Para os setores de celulose, papel e gráfica, máquinas e tratores, equipamentos eletrônicos e veículos, a hipótese nula de raiz unitária não é rejeitada para ambas as formas funcionais. Contudo, no setor de celulose, papel e gráfica a possibilidade de existência de múltiplas quebra fez com que fossem selecionados dois pontos de quebras distintos para as diferentes formas funcionais estimadas, o que novamente deve produzir uma redução do poder do teste de raiz unitária com uma quebra.

Como é possível perceber, existem dois agrupamentos de datas de quebra, escolhidas endogenamente pelos testes, que retratam dois fatos econômicos marcantes para a economia brasileira. O primeiro grupo situa-se em torno do final do ano de 1986 e do início do ano de 1987, correspondente à fase final do Plano Cruzado e à decretação da moratória em fevereiro de 1987, em que o quantum exportado foi restringido em razão de desequilíbrios e incertezas macroeconômicas internas, além de dificuldades de financiamento externo. O segundo agrupamento de datas, no início dos anos 1990, reflete o aprofundamento do processo de abertura comercial brasileira e do comércio regional na América do Sul, provocando um redirecionamento dos mercados e alterando as condições subjacentes à determinação do quantum exportado.

Portanto, para nove entre 13 setores analisados, foi rejeitada a hipótese nula de existência de uma raiz unitária em nível de significância de 5\%, tendo como alternativa, na maioria dos casos, a hipótese de existência de uma tendência determinista. Este resultado, associado aos períodos de quebra estimados endogenamente pelos testes de raiz unitária com o break, demonstra a existência de uma relação entre

\footnotetext{
${ }^{7}$ Em razão das séries utilizadas nestes testes já estarem dessazonalizadas, o número de defasagens máximas estabelecido foi igual a 4. O nível de significância utilizado é de $10 \%$.
} 
o período de recuperação da atividade exportadora no início dos anos de 1990 e o período de aprofundamento do processo de abertura comercial e integração regional no âmbito do Mercosul. Porém, o que não se verifica nas séries é uma posterior quebra em 1994, ou em 1995, ainda que se tenha verificado uma queda transitória das exportações nesse ano, em razão do aumento da demanda interna. A despeito da queda da rentabilidade da atividade exportadora promovida pela condução da política cambial no início do Plano Real, o que se verifica é um movimento de recuperação relativamente rápido, com a elevação de seus coeficientes de exportação, à medida que decresce o nível de absorção interna em alguns setores específicos, como elementos químicos, equipamentos eletrônicos, veículos, peças e outros veículos e calçados ${ }^{8}$

Tabela 6

Testes de raiz unitária com break: séries de quantum

\begin{tabular}{|c|c|c|c|c|c|}
\hline Setor & Modelo & Break & $t-$ theta & $t-$ alpha & $p$-value \\
\hline \multirow[t]{2}{*}{ Extrativa mineral } & Aom 1 & $1986: 4$ & 4,74685 & $-6,62014$ & $<0,01$ \\
\hline & Iom 1 & 1986:4 & 3,77379 & $-5,52500$ & $<0,01$ \\
\hline \multirow[t]{2}{*}{ Siderurgia } & Aom 0 & 1986:2 & - & $-5,14310$ & $<0,01$ \\
\hline & $\operatorname{Iom} 1$ & $1987: 2$ & 8,43885 & $-6,30717$ & $<0,01$ \\
\hline \multirow[t]{2}{*}{ Metais não-ferrosos } & Aom 2 & $1989: 3$ & 1,94270 & $-7,81846$ & $<0,01$ \\
\hline & $\operatorname{Iom} 2$ & 1991:2 & 4,41290 & $-6,73641$ & $<0,01$ \\
\hline \multirow[t]{2}{*}{ Máquinas e tratores } & Aom 2 & 1993:2 & 2,76179 & $-3,93020$ & 0,5685 \\
\hline & $\operatorname{Iom} 2$ & 1989:3 & 1,19434 & $-4,13504$ & 0,4383 \\
\hline \multirow[t]{2}{*}{ Material elétrico } & Aom 2 & $1992: 3$ & 7,58162 & $-5,12260$ & 0,0586 \\
\hline & $\operatorname{Iom} 2$ & 1992:3 & 4,00127 & $-4,93772$ & 0,0908 \\
\hline \multirow[t]{2}{*}{ Equipamentos eletrônicos } & Aom0 & 1988:04 & - & $-3,85694$ & 0,2142 \\
\hline & $\operatorname{Iom} 0$ & 1988:04 & $-1,53717$ & $-3,80855$ & 0,2361 \\
\hline \multirow[t]{2}{*}{ Veículos automotores } & Aom 2 & 1989:3 & $-3,03524$ & $-3,54130$ & 0,7985 \\
\hline & Iom 2 & 1989:4 & $-2,94035$ & $-3,86525$ & 0,6118 \\
\hline \multirow[t]{2}{*}{ Peças e outros veículos } & Aom 1 & $1989: 3$ & $-2,12412$ & $-5,61741$ & $<0,01$ \\
\hline & Iom 1 & 1992:3 & 10,83133 & $-7,9019$ & $<0,01$ \\
\hline \multirow[t]{2}{*}{ Madeira e mobiliário } & Aom0 & $1992: 3$ & - & $-4,64320$ & 0,0292 \\
\hline & $\operatorname{Iom} 0$ & 1992:2 & 4,29066 & $-4,57241$ & 0,0358 \\
\hline \multirow[t]{2}{*}{ Celulose, papel e gráfica } & Aom 1 & 1991:3 & 3,74579 & $-4,46426$ & 0,1454 \\
\hline & Iom 1 & 1987:1 & 1,13740 & $-4,30026$ & 0,2076 \\
\hline \multirow[t]{2}{*}{ Elementos químicos } & Aom 1 & $1987: 3$ & 2,35507 & $-6,02940$ & $<0,01$ \\
\hline & Iom 1 & $1987: 4$ & 3,87660 & $-6,65303$ & $<0,01$ \\
\hline \multirow[t]{2}{*}{ Têxtil } & Aom0 & $1986: 2$ & - & $-4,64069$ & 0,0292 \\
\hline & $\operatorname{Iom} 0$ & $1986: 4$ & 2,03170 & $-4,74986$ & 0,0214 \\
\hline \multirow[t]{2}{*}{ Calçados } & Aom0 0 & 1991:1 & - & $-4,92259$ & 0,0115 \\
\hline & $\operatorname{Iom} 0$ & 1992:1 & 4,45471 & $-5,36614$ & $<0,01$ \\
\hline
\end{tabular}

Obs.: $t$-theta corresponde à estatística $t$ para a variável dummy associada à quebra selecionada endogenamente; t-alpha corresponde à estatística $t$ associada ao coeficiente auto-regressivo do teste de raiz unitária.

Desse modo, para os setores em que foi rejeitada a hipótese de existência de uma raiz unitária, o que esta análise sugere é que a evolução do quantum

\footnotetext{
${ }^{8}$ Note que ainda que o teste de raiz unitária com break não seja capaz de detectar mais de um ponto de quebra, a existência de uma quebra estrutural em 1994 diminuiria o poder do teste, favorecendo a não-rejeição da hipótese nula de existência de uma raiz unitária para o índice em questão.
} 
exportado possui padrões de evolução deterministas, que são alterados em razão de mudanças estruturais, tais como fatores institucionais ou estratégicos dos setores exportadores, que determinam sua dinâmica por prazos mais longos, dificultando a verificação de uma relação de longo prazo estável com a rentabilidade da atividade exportadora.

\subsection{Testes de causalidade de Granger}

Levando em consideração a possível ordem de integração diferenciada entre as variáveis que compõem as funções de oferta e demanda de exportações, além da presença de quebras estruturais não apenas nas séries de quantum, apontadas pelos testes de raiz unitária, mas também nas séries de taxa de câmbio real, será testada a relação de longo prazo entre as variáveis representativas da taxa real de câmbio e os índices de quantum setoriais, por meio de testes de causalidade de Granger. ${ }^{9}$

São utilizadas duas definições distintas de taxa real de câmbio. A primeira, presente na função de oferta das exportações, expressa a taxa de câmbio real na ótica da lucratividade. Ou seja, sendo $p_{k}$ o logaritmo do índice de preços doméstico das exportações em moeda estrangeira das exportações nacionais para o setor $k$, e $c_{k^{d}}$ o respectivo logaritmo do índice de custos em moeda estrangeira do mesmo setor, a variável $\left(p_{k}^{e}-c_{k}^{d}\right)$ expressa um índice de rentabilidade do setor. A fim de reduzir possíveis problemas com a omissão de variáveis relevantes, será incluído na estimação do modelo VAR o índice do produto industrial do setor (prodin), que poderá captar um possível efeito tendencial expresso pela evolução do produto potencial do setor.

A segunda medida está incluída na função de demanda das exportações e expressa a taxa real de câmbio na ótica de competitividade das exportações nacionais em relação às exportações do resto mundo. Essa medida é dada pelo relativo de preços de exportação domésticos e internacionais, expresso pela variável $\left(p_{k}^{e}-p_{k}^{i}\right)$, em que $p_{k}^{e}$ e $p_{k}^{i}$ são, respectivamente, os logaritmos dos índices de preços doméstico e estrangeiro das exportações em moeda estrangeira para o setor $k$. Com o mesmo propósito de evitar o problema de omissão de variável relevante será incluída também na estimação do modelo VAR um indicador de demanda internacional do setor (demin).

Os testes de causalidade serão realizados para as variáveis em nível, seguindo a metodologia de Toda \& Yamamoto (1995). Esta metodologia permite que sejam

\footnotetext{
${ }^{9}$ A equivalência dos resultados dos testes utilizados aqui e a análise de co-integração, por meio do procedimento de Johansen (1988), é demonstrada em Caporale \& Pittis (1999).
} 
testadas restrições sobre os coeficientes de um modelo VAR em nível, utilizando distribuição assintótica de Wald padrão, sem que sejam consideradas restrições sobre a ordem de integração ou co-integração entre as variáveis do modelo.

A partir do vetor auto-regressivo não restrito (2), a idéia básica desta metodologia é aumentar artificialmente a ordem correta $k$ da equação (2) do modelo VAR em nível em uma ordem máxima suposta de integração das variáveis do modelo, $d_{\text {max }}$, de modo que o modelo estimado passe a ser de ordem $k+d_{\max }:{ }^{10}$

$$
\begin{gathered}
Z_{t}=\Phi_{0}+\Phi_{1} t+\Pi_{1} Z_{t-1}+\Pi_{2} Z_{t-2}+\ldots+\Pi_{k} Z_{t-k}+E_{t} \\
t=1,2, \ldots, T
\end{gathered}
$$

em que $E_{t} \sim N(0, \Omega)$ e $\Pi$ é uma matriz $(n \times n)$ de parâmetros.

Esta hipótese pode ser formulada como restrições sobre os coeficientes do modelo (2):

$$
H_{0}: f(\pi)=0
$$

em que $\pi=\operatorname{vec}(P),{ }^{11} P=\left[\Pi_{1}, \ldots ., \Pi_{k}\right)$ e $f(\cdot)$ é um vetor $m$ de funções satisfazendo a suposição de que seja duplamente contínua diferenciável com $\operatorname{rank}(F(\cdot))=m$ na vizinhança do valor verdadeiro do parâmetro $\pi$, sendo $F(\phi)=\partial f(\phi) / \partial \phi$.

Assuma que a ordem máxima de integração que se espera das variáveis seja 1 , isto é, $d_{\max }=1$, de modo que o modelo VAR a ser estimado possui nível de defasagem $p \geq k+d_{\max }=k+1$. Ou seja,

$$
Z_{t}=\hat{\Phi}_{0}+\hat{\Phi}_{1} t+\hat{\Pi}_{1} Z_{t-1}+\ldots+\hat{\Pi}_{k} Z_{t-k}+\hat{\Pi}_{k+1} Z_{t-k-1}+\ldots+\hat{\Pi}_{p} Z_{t-p}+\hat{E}_{t}
$$

em que o circunflexo $\left({ }^{\wedge}\right)$ denota a estimação por M.Q.O.

A restrição sobre os parâmetros (3) não envolve as matrizes $\Pi_{t-k-1}, \ldots, \Pi_{t-p}$, já que estas são zero sob a hipótese de que a verdadeira ordem de defasagem é $k$.

\footnotetext{
${ }^{10}$ Toda \& Yamamoto (1995) consideram ainda uma formulação genérica em que podem ser incluídos no modelo termos de tendência determinista de ordem $q$, além de dummies sazonais. Por conveniência de notação, o modelo é restrito e terá apenas uma tendência linear.

${ }^{11} \operatorname{vec}(\mathrm{P})$ é a notação utilizada para um conjunto de linhas de uma matriz $\mathrm{P}$ organizadas na forma de um vetor coluna.
} 
A equação (4) pode ser reescrita de forma mais compacta como se segue:

$$
Z_{t}=\hat{\Phi} \tau_{t}+\hat{P} x_{t}+\hat{\Psi} y_{t}+\hat{E}_{t}
$$

em que

$$
\begin{gathered}
\hat{\Phi}=\left[\Phi_{0}, \Phi_{1}\right], \tau_{t}=[1, t], x_{t}=\left[Z_{t-1}^{\prime}, \ldots, Z_{t-k}^{\prime}\right], y_{t}=\left[Z_{t-k-1}^{\prime}, \ldots, Z_{t-p}^{\prime}\right], \\
\hat{P}=\left[\hat{\Pi}_{1}, \ldots, \hat{\Pi}_{k}\right] \text { e } \hat{\Psi}=\left[\hat{\Pi}_{k+1}, \ldots, \hat{\Pi}_{p}\right]
\end{gathered}
$$

ou, ainda, em forma matricial:

$$
Z^{\prime}=\hat{\Phi} T^{\prime}+\hat{P} X^{\prime}+\hat{\Psi} Y^{\prime}+\hat{E}^{\prime}
$$

em que $X=[x 1, \ldots, x T]^{\prime}$ e assim por diante.

Assim, é possível construir a estatística de Wald para testar a hipótese (3):

$$
W=f(\hat{\pi})^{\prime}\left[F(\hat{\pi})^{\prime}\left\{\hat{\sum}_{E} \otimes\left(X^{\prime} Q X\right)^{-1}\right\} F(\hat{\pi})^{\prime}\right]^{-1} f(\hat{\pi})^{\prime}
$$

em que $\hat{\sum}_{E}=T^{-1} \hat{E}^{\prime} \hat{E}, Q=Q_{\tau}-Q_{\tau} Y\left(Y^{\prime} Q_{\tau} Y\right)_{T}^{-1} Y^{\prime} Q_{\tau}$ e $Q_{\tau}=I_{T}-T\left(T^{\prime} T\right)^{-1} T^{\prime}$.

Toda \& Yamamoto (1995) demonstram que, sob a hipótese nula (3), a estatística de Wald (6) tem uma distribuição assintótica qui-quadrado com $m$ graus de liberdade se $p \geq k+d$, não importando a ordem de integração das variáveis ou a presença de relação de co-integração entre elas. ${ }^{12}$ Adicionalmente, demonstram que os procedimentos usuais de seleção de ordem de defasagem do modelo VAR são válidos também, não importando a ordem de integração das variáveis, contanto que $m \geq k \geq d$.

Admitindo que a ordem de integração máxima das variáveis consideradas nos testes de causalidade é 1 , isto é, $Z_{t} \sim I(1)$, de modo que para os modelos estimados $d_{\text {max }}$ será igual a 1 . Os modelos VAR foram selecionados de acordo com os critérios

\footnotetext{
${ }^{12}$ No entanto, como nota de precaução, Toda \& Yamamoto (1995) alertam que a introdução de defasagens adicionais implica perda de poder dos testes, sendo esta perda tanto menor quanto maior a ordem $k$ do modelo. Esses autores lembram, ainda, que, em razão da equivalência assintótica entre os testes de Wald e razão de verossimilhança (LR), este último teste pode ser empregado de modo similar.
} 
de informação BIC (Schwarz), AIC (Akaike) e HQ (Hannan-Quinn), considerandose adicionalmente a qualidade dos resíduos expressa pelos testes de diagnóstico de ausência de autocorrelação e normalidade e homocedasticidade dos resíduos, além de testes $\mathrm{F}$ seqüenciais, sendo 5 o nível inicial de defasagens na formulação dos modelos. ${ }^{13}$ Com relação aos procedimentos de testes, em razão da possibilidade de comportamentos distintos em amostras finitas dos testes de Wald e razão de verossimilhança (LR) foram realizados testes de causalidade por meio dos dois procedimentos de testes. Os respectivos vetores $Z_{t}^{\prime}$ considerados no modelo (3) são iguais a $Z^{\prime}=\left[Q_{K}^{E},\left(p_{k}^{E}-c_{k}^{d}\right)\right.$,prodin $]$ e $Z^{\prime}=\left[Q_{K}^{E},\left(p_{k}^{E}-p_{k}^{I}\right)\right.$,demin $]$.

Os testes de causalidade, apresentado na tabela 7 , rejeitaram a hipótese nula de não-causalidade de uma das medidas representativas de taxa real de câmbio em nível de significância de $5 \%$ para os setores de extrativa mineral, máquinas e tratores, material elétrico, veículos, e madeira e mobiliário. Em nível de significância de 10\%. uma das hipóteses nulas também foi rejeitada para o setor têxtil. Portanto, para 7 entre os 13 setores, em nível de significância de ao menos 10\%, não foi possível observar uma relação estável de precedência temporal de longo prazo entre os estímulos produzidos, sobre a oferta ou a demanda de bens exportados manufaturados, pelo nível de rentabilidade ou pelo nível de preços relativos, e a quantidade efetivamente exportada por estes setores exportadores de bens manufaturados. Adicionalmente, Kannebley (2000) mostra para o período de 1985-I a 1997-IV, por meio de testes de raiz unitária e análise de co-integração, que as séries dos relativos de preços $\left(p_{k}^{e}-p_{k}^{i}\right)$ para os setores de extrativa mineral, madeira e mobiliário, e veículos automotores são estacionárias. Estes resultados indicam, portanto, que essas medidas de taxa de câmbio não são responsáveis por alterações no componente de tendência das respectivas séries de quantum exportados desses setores.

Já para o mesmo conjunto de setores, em ao menos um nível de significância de 10\%, foi possível detectar uma relação de longo prazo entre o produto industrial do setor e o quantum exportado, para os setores de extrativa mineral, siderurgia, metais não-ferrosos, madeira e mobiliário, e celulose, papel e gráfica. Notadamente, esses são setores na maioria semimanufaturados, em que predominam a alta intensidade do capital e/ou do uso dos recursos naturais. A importância desses tipos de setores na caracterização da evolução do quantum exportado é destacada por Iglesias (2001), que defende o argumento de que as restrições ao aumento

\footnotetext{
${ }^{13}$ A fim de evitar instabilidade nas equações estimadas e evidências espúrias de causalidade, utilizou-se, anteriormente à estimação dos modelos VAR, o procedimento de Harvey \& Koopman (1992) para a detecção de outliers nas séries. No anexo são apresentados testes de diagnóstico para os modelos VAR estimados, além de informações concernentes às ordens de defasagem selecionadas e ao critério de informação de Schwarz para os modelos estimados.
} 
da capacidade produtiva foram um dos principais impedimentos à expansão da oferta exportadora no período de 1985 a 1998. Também foi rejeitada a hipótese de ausência de causalidade de longo prazo em nível de significância de $5 \%$ entre o indicador da demanda setorial e o seu quantum exportado para os setores de material elétrico, equipamentos eletrônicos e veículos automotores. Somente para os setores de máquinas e tratores, peças e outros veículos, elementos químicos, têxtil e calçados não foi rejeitada a hipótese de ausência de causalidade de longo prazo em nível ao menos de $10 \%$ de significância.

Tabela 7

Teste de causalidade de Granger

\begin{tabular}{|c|c|c|c|c|}
\hline Hipótese nula & \multicolumn{2}{|c|}{$\begin{array}{l}\text { Rentabilidade não-Granger - } \\
\text { Causa quantum exportado }\end{array}$} & \multicolumn{2}{|c|}{$\begin{array}{l}\text { Relativo de preços não-Granger - } \\
\text { Causa quantum exportado }\end{array}$} \\
\hline Setor & Est. de Wald & Est. LR & Est. de Wald & Est. LR \\
\hline \multirow[t]{2}{*}{ Extrativa mineral } & 2,5124 & 3,50798 & 6,7151 & 8,26109 \\
\hline & {$[0,4731]$} & {$[0,3197]$} & {$[0,0348]^{* *}$} & {$[0,0161]^{* *}$} \\
\hline \multirow[t]{2}{*}{ Siderurgia } & 4,8766 & 7,45097 & 0,58468 & 0,830973 \\
\hline & {$[0,3002]$} & {$[0,1139]$} & {$[0,7465]$} & {$[0,6600]$} \\
\hline \multirow[t]{2}{*}{ Metais não-ferrosos } & 3,4093 & 5,11245 & 2,1044 & 2,52285 \\
\hline & {$[0,3327]$} & {$[0,1637]$} & {$[0,1469]$} & {$[0,1122]$} \\
\hline \multirow[t]{2}{*}{ Máquinas e tratores } & 8,4444 & 11,0229 & 4,0544 & 5,0204 \\
\hline & {$[0,0377]^{* *}$} & {$[0,0116]^{*}$} & {$[0,0441]^{* *}$} & {$[0,0251]^{* *}$} \\
\hline \multirow[t]{2}{*}{ Material elétrico } & 1,6107 & 2,71944 & 7,7323 & 10,9468 \\
\hline & {$[0,6570]$} & {$[0,4369]$} & {$[0,0519]^{*}$} & {$[0,0120]^{* *}$} \\
\hline \multirow[t]{2}{*}{ Equipamentos eletrônicos } & 0,98359 & 1,2632 & 2,2443 & 3,23178 \\
\hline & {$[0,3213]$} & {$[0,2610]$} & {$[0,5233]$} & {$[0,3573]$} \\
\hline \multirow[t]{2}{*}{ Veículos automotores } & 6,1912 & 8,69894 & 5,1067 & 6,85234 \\
\hline & {$[0,1027]$} & {$[0,0336]^{* *}$} & {$[0,0778]^{*}$} & {$[0,0325]^{* *}$} \\
\hline \multirow[t]{2}{*}{ Peças e outros veículos } & 0,090463 & 0,116185 & 2,7183 & 3,40232 \\
\hline & {$[0,7636]$} & {$[0,7332]$} & {$[0,2569]$} & {$[0,1825]$} \\
\hline \multirow[t]{2}{*}{ Madeira e mobiliário } & 3,9235 & 5,37915 & 6,4901 & 7,96911 \\
\hline & {$[0,2698]$} & {$[0,1460]$} & {$[0,0390]^{* *}$} & {$[0,0186]^{* *}$} \\
\hline \multirow[t]{2}{*}{ Celulose, papel e gráfica } & 1,3212 & 1,64157 & 0,15222 & 0,1784 \\
\hline & {$[0,5165]$} & {$[0,4401]$} & {$[0,6964]$} & {$[0,6728]$} \\
\hline \multirow[t]{2}{*}{ Elementos químicos } & 3,0853 & 4,39294 & 0,22621 & 0,264903 \\
\hline & {$[0,3787]$} & {$[0,2220]$} & {$[0,6343]$} & {$[0,6068]$} \\
\hline \multirow[t]{2}{*}{ Têxtil } & 5,0539 & 7,0136 & 1,4986 & 2,04999 \\
\hline & {$[0,1679]$} & {$[0,0715]^{*}$} & {$[0,4727]$} & {$[0,3588]$} \\
\hline \multirow[t]{2}{*}{ Calçados } & 0,80136 & 0,877913 & 0,22628 & 0,283418 \\
\hline & {$[0,3707]$} & {$[0,3488]$} & {$[0,6343]$} & {$[0,5945]$} \\
\hline
\end{tabular}

Obs.: Os valores entre colchetes correspondem aos de probabilidade dos testes.

Esses resultados de ausência de causalidade das variáveis de produção física e demanda internacional podem ser explicados pelos diversos processos de reestruturação industrial sofridos por esses setores com a intensificação da abertura comercial. $^{14}$

\footnotetext{
${ }^{14}$ Kannebley (1999) demonstra, por meio de estimação de modelos ADL, para os casos dos
} 
Tabela 8

Teste de causalidade de Granger

\begin{tabular}{lcccc}
\hline \multirow{2}{*}{ Hipótese nula } & \multicolumn{2}{c}{ Demanda não-Granger -} & \multicolumn{2}{c}{ Produção não-Granger - } \\
& Causa quantum & exportado & \multicolumn{2}{c}{ Causa quantum exportado } \\
\hline Setor & Est. de Wald & Est. LR & Est. de Wald & Est. LR \\
\hline Extrativa mineral & 0,37501 & 0,497632 & 10,602 & 13,4229 \\
Siderurgia & {$[0,8290]$} & {$[0,7797]$} & {$[0,0141]^{* *}$} & {$[0,0038]^{* * *}$} \\
& 2,5329 & 3,5094 & 14,6 & 19,6817 \\
Metais não-ferrosos & {$[0,2818]$} & {$[0,1730]$} & {$[0,0056]^{* * *}$} & {$[0,0006]^{* * *}$} \\
& 0,020839 & 0,0255725 & 9,1971 & 13,8062 \\
Máquinas e tratores & {$[0,8852]$} & {$[0,8729]$} & {$[0,0268]^{* *}$} & {$[0,0032]^{* * *}$} \\
& 0,16322 & 0,211749 & 2,3638 & 3,33307 \\
Material elétrico & {$[0,6862]$} & {$[0,6454]$} & {$[0,5004]$} & {$[0,3431]$} \\
& 19,797 & 24,4368 & 4,345 & 7,0334 \\
Equipamentos eletrônicos & {$[0,0002]^{* * *}$} & {$[0,0000]^{* * *}$} & {$[0,2265]$} & {$[0,0708]$} \\
& 7,2565 & 9,7973 & 2,2309 & 2,82222 \\
Veículos automotores & {$[0,0642]^{* *}$} & {$[0,0204]^{* *}$} & {$[0,1353]$} & {$[0,0930]$} \\
Peças e outros veículos & 10,175 & 12,8767 & 2,7695 & 4,07202 \\
& {$[0,0062]^{* * *}$} & {$[0,0016]^{* * *}$} & {$[0,4285]$} & {$[0,2538]$} \\
Madeira e mobiliário & 1,1603 & 2,25765 & 0,26472 & 0,339283 \\
& {$[0,5598]$} & {$[0,3234]$} & {$[0,6069]$} & {$[0,5602]$} \\
Celulose, papel e gráfica & 1,0786 & 1,41027 & 8,7374 & 11,2991 \\
& {$[0,5831]$} & {$[0,4940]$} & {$[0,0330]^{* *}$} & {$[0,0102]^{* *}$} \\
Elementos químicos & 0,041394 & 0,048571 & 4,0609 & 4,8916 \\
Têxtil & {$[0,8388]$} & {$[0,8256]$} & {$[0,1313]$} & {$[0,0867]^{*}$} \\
Calçados & 0,070397 & 0,0825787 & 0,6823 & 1,00395 \\
& {$[0,7908]$} & {$[0,7738]$} & {$[0,8774]$} & {$[0,8003]$} \\
\hline Obs: Os & 2,7166 & 3,6596 & 3,0118 & 4,29256 \\
& {$[0,2571]$} & {$[0,1604]$} & {$[0,3898]$} & {$[0,2316]$} \\
& 0,60226 & 0,75113 & 0,33476 & 0,418774 \\
& {$[0,4377]$} & {$[0,3861]$} & {$[0,5629]$} & {$[0,5175]$} \\
\hline
\end{tabular}

Obs.: Os valores entre colchetes correspondem aos de probabilidade dos testes.

\section{Considerações Finais}

Este artigo procurou demonstrar a importância da evolução do volume exportado na determinação do valor exportado e sua baixa relação de longo prazo com a evolução de medidas alternativas de taxa real de câmbio.

Por meio de análise descritiva percebeu-se que há uma relação entre a evolução

setores de calçados e peças e outros veículos a presença de instabilidade nas equações estimadas para o quantum exportado desses setores, destacando a alteração nos determinantes do quantum exportado a partir de 1990. Ainda é importante destacar que, na estimação da equação para o setor de calçados, a variável preço em moeda estrangeira apresenta-se significativa, porém o valor do parâmetro se altera nos subperíodos de 1984 a 1990 e 1990 a 1997, enquanto a variável de produto tendencial do setor é significativa somente para subperíodo de 1984 a 1990. Para mais informações sobre esses setores, ver, entre outros, Ferraz et al. (1995), Hollanda Filho (1996), Constanzi (1999) e Iglesias (2001). 
do quantum exportado e os processos de abertura comercial de integração regional. Os testes de raiz unitária com break corroboram este argumento ao demonstrarem a característica tendência estacionária das séries de índices de quantum e os agrupamentos de pontos de quebra em dois períodos distintos: o primeiro corresponde ao final do Plano Cruzado, quando o ambiente econômico está permeado de grande incerteza e com restrições sobre o financiamento externo em razão da moratória decretada no primeiro trimestre de 1987; o segundo agrupamento é justamente no início dos anos 1990, com a intensificação da abertura comercial, que ocorreu conjuntamente com o aprofundamento dos movimentos de integração regional.

Ademais, concluiu-se que, a despeito da instabilidade da política cambial, não foi possível para 7 dos 13 setores analisados, em um nível de $10 \%$ de significância, estabelecer uma relação de longo prazo estatisticamente significante entre a evolução do quantum e os indicadores de rentabilidade e competitividade das exportações. Este resultado foi produzido pelos testes de causalidade de Granger, quando conduzidos para duas medidas de taxas de câmbio setoriais, representativas da rentabilidade e da competitividade dos setores exportadores, e os respectivos índices setoriais de quantum exportado.

O conjunto de testes econométricos realizados revela a predominância de fatores inerciais que determinam a evolução do quantum exportado ao longo do tempo. A ausência de relação de longo prazo entre as alternativas medidas de taxa real de câmbio e o quantum exportado não deve ser interpretada como um contra-senso à teoria econômica convencional, mas sim como fruto da dominância de outros fatores institucionais e/ou estruturais na determinação da evolução do quantum exportado. Esta argumentação vai ao encontro das conclusões da análise empreendida por Iglesias (2001) sobre as causas do baixo dinamismo das exportações de produtos industrializados no período de 1985 a 1998, em que é ressaltada a importância das restrições impostas pela expansão da capacidade produtiva da indústria na determinação de sua capacidade exportadora, e como a abertura comercial atuou no sentido de aliviar as tensões existentes entre a demanda doméstica e externa.

Esta análise não permite tecer comentários sobre em que medida a política cambial deve ser julgada adequada ou inadequada à promoção das exportações. O que se procura ressaltar aqui é que estes critérios devem ser estabelecidos considerando um ambiente econômico e institucional mais amplo. Neste sentido as discussões a respeito do impacto da recente desvalorização cambial sobre o desempenho exportador e a própria sustentabilidade das contas externas, apoiadas no incremento das receitas em moeda estrangeira provenientes das exportações, devem ser acompanhadas da discussão sobre o ambiente institucional subjacente ao 
comércio exterior brasileiro e da expansão da capacidade produtiva da indústria. A permanecer este padrão de evolução do quantum exportado, medidas que fortaleçam e facilitem as relações comerciais internacionais, bem como a promoção de políticas internas que favoreçam a expansão da produtividade e do produto potencial exportador, devem ser incentivadas, a fim de que os incentivos promovidos pela desvalorização da taxa real de câmbio traduzam-se na efetivação ao longo do tempo de uma taxa de crescimento superior àquelas verificadas durante os anos de 1980 e 1990.

\section{Referências}

Bonneli, R. \& Fonseca, R. (1998). Competitividade da indústria nos anos 90. Revista Brasileira de Comércio Exterior, (55):41-7.

Bonomo \& Terra, M. (1999). The political economy of exchange rate policy in Brazil: 1964-1997. Ensaios Econômicos EPGE, (347).

Britto, J. N. P. (1993). Estudos da competitividade da industria brasileira: Competitividade da industria de alumínio.

Campbell, J. Y. \& Perron, P. (1991). Pitfalls and opportunities: What macroeconomists should know about unit roots. NBER Macroeconomics Annual, pages 141-201. In: Blanchard, Olivier J. and Fischer, Stanley (eds.).

Caporale, G. M. \& Pittis, N. (1999). Efficient estimation of cointegrating vectors and testing for causality in vector autoregressions. Journal of Economic Surveys, $(13(1)): 1-35$.

Constanzi, R. N. (1999). Distribuição espacial da indústria de calçados no brasil no século XX. Master's thesis, FEA/USP, São Paulo.

Dickey, D. A. \& Fuller, W. A. (1979). Distribution of the estimators for autoregressive time series with a unit root. Journal of the Statistical Association, $(74(366)): 427-31$.

Dickey, D. A. \& Fuller, W. A. (1981). Likelihood ratio statistics for autoregressive time series with a unit root. Econometrica, (49):1057-72.

Ferraz, J. C., Kupffer, D., \& Haguenauer, L. (1995). Made in Brazil: Desafios Competitivos Para a Indústria. Campus, Rio de Janeiro. 
Guimarães, E. A. (1995). Taxas de câmbio setoriais, metodologia e resultados. Texto para Discussão, 106.

Guimaraes, E. A., Pinheiro, A. C., Falcão, C., Pourchet, H., \& Markwald, E. R. (1997). Índices de preço e quantum das exportações brasileiras. Texto para Discussão, 121.

Haguenauer, L., Markwald, E. R., \& Pourchet, H. (1998). Estimativas do valor da produção industrial e elaboração de coeficientes de exportação e importação da indústria brasileira (1985-1996). Texto para Discussão, 563.

Harvey, A. C. \& Koopman, S. J. (1992). Diagnostic checking of unobserved components time series. Journal of Business and Economic Statistics, (10):377-89.

Holland, M. (1996). Taxas de câmbio e regimes cambiais no Brasil. In: Encontro da Anpec. Anais.

Hollanda Filho, S. B. (1996). Os desafios da indústria automobilística: A crise da modernização.

Horta, M. H., Piani, G., \& Kume, H. (1991). Política cambial e comercial. In: Perspectivas da economia brasileira - 1992.

Iglesias, R. (2001). Baixo dinamismo das exportações de produtos industrializados ou baixo crescimento da produção industrial? Revista Brasileira de Comércio Exterior, page 67.

Johansen, S. (1988). Statistical analysis of cointegration vectors. Journal of Economic Dynamics and Control, (12):231-54.

Kannebley, Jr., S. (1999). Política cambial e exportações: Uma análise empírica. Tese de Doutorado.

Kannebley, Jr., S. (2000). Exchange rate pass-through: Uma análise setorial para as exportações brasileiras 1984-1997. Revista de Economia Aplicada, (4(3)):43564.

MacKinnon, J. G. (1991). Critical Values for Cointegration Tests. Oxford University Press. In: Engle, R. F. and Granger, C. W. J. (eds.). Long-run economic relationships: readings in cointegration.

Moreira, M. M. (1999). A indústria brasileira nos anos 90. O que já se pode dizer? Technical report, BNDES. 
Nonnenberg, M. J. (1998). Competitividade e crescimento das exportações brasileiras. Technical report, Ipea, Rio de Janeiro. Texto para Discussão, 578.

Perron, P. (1993). Trend, Unit Root and Structural Change in Macroeconomic Time Series. Macmillan Press, Basingstoke. In: Rao, B. B. (ed.).

Perron, P. \& Vogelsang, T. J. (1992). Nonstationarity and level shifts with an application to purchasing power parity. Journal of Business and Economic Statistics, (10):301-20.

Pinheiro, A. C. \& Horta, M. H. (1992). A competitividade das exportações brasileiras no período 1980/88. Pesquisa e Planejamento Econômico, (22(3)):437-74.

Thorstensen, V. (1996). Desafios para o brasil no comércio internacional: Análise do desempenho do comércio externo e do investimento direto no brasil. Revista Brasileira de Comércio Exterior, (49):54-64.

Toda, H. Y. \& Yamamoto, T. (1995). Statistical inference in vector autoregressions with possibly integrated processes. Journal of Econometrics, (66):225-50.

Zini, Jr., A. A. (1993). Taxa de Câmbio e Política Cambial No Brasil. Edusp, São Paulo. 


\section{Anexo}

Tabela A.1

Relativo do valor das exportações

\begin{tabular}{lrrrrrrr} 
& 1985 & 1986 & 1987 & 1988 & 1989 & 1990 & 1991 \\
\hline Total & 80,7 & 70,6 & 82,9 & 107,6 & 109,5 & 100 & 100,7 \\
Extrativa mineral & 66,4 & 64,2 & 64,6 & 78,5 & 92,0 & 100,0 & 107,7 \\
Siderurgia & 60,7 & 53,3 & 56,3 & 113,1 & 124,6 & 100,0 & 115,9 \\
Metais não-ferrosos & 36,0 & 42,3 & 59,6 & 108,6 & 105,0 & 100,0 & 104,8 \\
Máquinas e tratores & 66,0 & 63,0 & 77,3 & 110,5 & 127,9 & 100,0 & 106,0 \\
Material elétrico & 43,2 & 51,5 & 59,4 & 80,5 & 102,5 & 100,0 & 110,4 \\
Equipamentos eletrônicos & 87,7 & 114,1 & 115,5 & 128,7 & 119,0 & 100,0 & 101,0 \\
Veículos automotores & 95,9 & 74,7 & 165,3 & 179,1 & 160,4 & 100,0 & 94,3 \\
Peças e outros veículos & 58,1 & 55,8 & 71,7 & 83,1 & 102,0 & 100,0 & 96,1 \\
Madeira e mobiliário & 70,7 & 74,0 & 92,9 & 117,2 & 97,8 & 100,0 & 107,3 \\
Celulose, papel e gráfica & 45,5 & 56,2 & 63,6 & 108,5 & 106,0 & 100,0 & 102,5 \\
Elementos químicos & 57,6 & 62,8 & 58,0 & 83,0 & 99,5 & 100,0 & 95,6 \\
Têxtil & 81,8 & 70,6 & 98,8 & 102,3 & 110,2 & 100,0 & 112,4 \\
Calçados & 76,3 & 78,0 & 92,4 & 112,0 & 106,0 & 100,0 & 105,3 \\
\hline & & & & & & & \\
\hline & 1992 & 1993 & 1994 & 1995 & 1996 & 1997 & 1998 \\
\hline Total & 113,9 & 122,8 & 138,6 & 148,0 & 152,0 & 168,7 & 162,8 \\
Extrativa mineral & 96,0 & 96,1 & 97,2 & 107,3 & 113,3 & 120,3 & 134,9 \\
Siderurgia & 116,1 & 119,6 & 116,2 & 121,4 & 119,0 & 108,1 & 102,1 \\
Metais não-ferrosos & 112,5 & 105,4 & 121,1 & 152,0 & 151,0 & 148,6 & 116,4 \\
Máquinas e tratores & 130,7 & 160,3 & 194,6 & 205,2 & 202,0 & 233,1 & 212,9 \\
Material elétrico & 129,1 & 153,4 & 156,2 & 177,6 & 173,2 & 174,5 & 167,0 \\
Equipamentos eletrônicos & 107,7 & 106,9 & 106,0 & 111,5 & 135,3 & 160,3 & 159,0 \\
Veículos automotores & 180,5 & 163,3 & 163,7 & 123,8 & 143,2 & 279,4 & 313,8 \\
Peças e outros veículos & 110,1 & 121,4 & 141,3 & 137,8 & 154,3 & 182,6 & 205,0 \\
Madeira e mobiliário & 145,8 & 230,1 & 281,0 & 299,5 & 305,6 & 334,4 & 306,2 \\
Celulose, papel e gráfica & 119,9 & 126,7 & 148,1 & 221,6 & 158,7 & 163,9 & 163,2 \\
Elementos químicos & 110,1 & 115,5 & 117,9 & 145,3 & 182,8 & 185,2 & 179,0 \\
Têxtil & 119,8 & 109,8 & 111,5 & 117,9 & 103,5 & 103,4 & 91,3 \\
Calçados & 126,7 & 158,5 & 141,8 & 141,0 & 158,6 & 159,7 & 141,6 \\
\hline Font: Funcos & & & & & & &
\end{tabular}

Fonte: Funcex. 
Tabela A.2

Índice de quantum das exportações

\begin{tabular}{|c|c|c|c|c|c|c|c|}
\hline & 1985 & 1986 & 1987 & 1988 & 1989 & 1990 & 1991 \\
\hline Total & 94,4 & 79,4 & 93,0 & 107,7 & 94,4 & 100,0 & 102,5 \\
\hline Extrativa mineral & 79,0 & 77,5 & 79,9 & 96,5 & 101,6 & 100,0 & 101,3 \\
\hline Siderurgia & 77,2 & 67,1 & 68,8 & 114,4 & 110,6 & 100,0 & 114,2 \\
\hline Metais não-ferrosos & 41,8 & 55,2 & 65,6 & 85,6 & 86,4 & 100,0 & 123,7 \\
\hline Máquinas e tratores & 93,5 & 85,2 & 97,6 & 123,7 & 142,1 & 100,0 & 110,3 \\
\hline Material elétrico & 61,1 & 72,8 & 78,0 & 95,8 & 111,8 & 100,0 & 108,7 \\
\hline Equipamentos eletrônicos & 98,6 & 112,1 & 109,0 & 121,4 & 125,1 & 100,0 & 96,1 \\
\hline Veículos automotores & 139,1 & 103,8 & 201,3 & 199,5 & 169,2 & 100,0 & 88,5 \\
\hline Peças e outros veículos & 82,0 & 73,5 & 97,6 & 104,8 & 114,9 & 100,0 & 93,6 \\
\hline Madeira e mobiliário & 76,6 & 83,9 & 74,2 & 110,6 & 96,8 & 100,0 & 120,8 \\
\hline Celulose, papel e gráfica & 60,1 & 65,7 & 62,7 & 82,9 & 93,5 & 100,0 & 95,8 \\
\hline Elementos químicos & 105,8 & 88,8 & 107,8 & 104,6 & 119,5 & 100,0 & 112,5 \\
\hline Têxtil & 93,3 & 93,8 & 96,3 & 113,8 & 111,0 & 100,0 & 91,9 \\
\hline Calçados & 94,4 & 79,4 & 93,0 & 107,7 & 94,4 & 100,0 & 102,5 \\
\hline & 1992 & 1993 & 1994 & 1995 & 1996 & 1997 & 1998 \\
\hline Total & 120,0 & 139,8 & 142,7 & 134,1 & 137,6 & 151,7 & 157,0 \\
\hline Extrativa mineral & 95,6 & 106,1 & 116,8 & 116,8 & 116,2 & 121,1 & 133,9 \\
\hline Siderurgia & 124,1 & 126,8 & 104,8 & 104,8 & 110,8 & 98,7 & 98,6 \\
\hline Metais não-ferrosos & 137,1 & 139,9 & 147,2 & 147,2 & 158,7 & 159,0 & 142,3 \\
\hline Máquinas e tratores & 127,8 & 172,3 & 186,8 & 186,8 & 187,6 & 206,6 & 187,9 \\
\hline Material elétrico & 125,4 & 165,1 & 164,4 & 164,4 & 148,4 & 149,0 & 143,8 \\
\hline Equipamentos eletrônicos & 96,3 & 97,3 & 85,1 & 85,1 & 101,5 & 123,9 & 122,6 \\
\hline Veículos automotores & 162,5 & 155,7 & 104,5 & 104,5 & 115,2 & 222,7 & 241,7 \\
\hline Peças e outros veículos & 104,5 & 149,2 & 135,9 & 135,9 & 139,6 & 168,1 & 183,7 \\
\hline Madeira e mobiliário & 145,4 & 196,6 & 165,7 & 165,7 & 177,1 & 196,4 & 202,1 \\
\hline Celulose, papel e gráfica & 114,6 & 126,5 & 139,5 & 139,5 & 163,4 & 167,2 & 169,5 \\
\hline Elementos químicos & 128,3 & 128,8 & 108,7 & 108,7 & 93,3 & 92,6 & 87,2 \\
\hline Têxtil & 117,1 & 160,9 & 120,5 & 120,5 & 133,8 & 138,4 & 130,4 \\
\hline Calçados & 120,0 & 139,8 & 142,7 & 134,1 & 137,6 & 151,7 & 157,0 \\
\hline
\end{tabular}

Fonte: Funcex. 
Tabela A.3

Testes de diagnóstico: modelo VAR quantum $\mathrm{X}$ rentabilidade

\begin{tabular}{|c|c|c|c|c|c|c|}
\hline Setor & & $\mathrm{k}$ & AR1-4 & Normal & HET & $\mathrm{BIC}$ \\
\hline \multirow[t]{4}{*}{ Extrativa mineral } & $\mathrm{d}$ & 3 & 1,916 & 6,3708 & 0,48932 & $-15,414$ \\
\hline & & & {$[0,0093]$} & {$[0,3830]$} & {$[0,9998]$} & \\
\hline & $d+1$ & 4 & 1,7928 & 4,7874 & 0,17704 & $-14,885$ \\
\hline & & & {$[0,0203]$} & {$[0,5713]$} & {$[1,0000]$} & \\
\hline \multirow[t]{4}{*}{ Siderurgia } & d & 4 & 0,84884 & 3,9449 & 0,076568 & $-14,172$ \\
\hline & & & {$[0,6974]$} & {$[0,6841]$} & {$[1,0000]$} & \\
\hline & $d+1$ & 5 & 1,0628 & 3,1516 & 0,036085 & $-13,550$ \\
\hline & & & {$[0,4157]$} & {$[0,7896]$} & {$[1,0000]$} & \\
\hline \multirow[t]{4}{*}{ Metais não-ferrosos } & d & 3 & 1,9122 & 10,496 & 0,60044 & $-13,513$ \\
\hline & & & {$[0,0115]$} & {$[0,1053]$} & {$[0,9924]$} & \\
\hline & $d+1$ & 4 & 1,2347 & 6,3827 & 0,20161 & $-13,499$ \\
\hline & & & {$[0,2356]$} & {$[0,3817]$} & {$[1,0000]$} & \\
\hline \multirow[t]{4}{*}{ Máquinas e tratores } & $\mathrm{d}$ & 3 & 2,1026 & 2,6359 & 0,6268 & $-12,904$ \\
\hline & & & {$[0,0038]$} & {$[0,8530]$} & {$[0,9894]$} & \\
\hline & $d+1$ & 4 & 2,1928 & 6,762 & 0,3007 & $-12,678$ \\
\hline & & & {$[0,0032]$} & {$[0,3434]$} & {$[1,0000]$} & \\
\hline \multirow[t]{4}{*}{ Material elétrico } & $\mathrm{d}$ & 3 & 1,2552 & 9,3238 & 0,42167 & $-14,177$ \\
\hline & & & {$[0,2190]$} & {$[0,1562]$} & {$[0,9999]$} & \\
\hline & $d+1$ & 4 & 1,2108 & 9,258 & 0,065066 & $-13,674$ \\
\hline & & & {$[0,2654]$} & {$[0,1596]$} & {$[1,0000]$} & \\
\hline \multirow[t]{4}{*}{ Equipamentos eletrônicos } & d & 2 & 0,86652 & 11,139 & 0,97003 & $-13,377$ \\
\hline & & & {$[0,6789]$} & {$[0,0842]$} & {$[0,5553]$} & \\
\hline & $d+1$ & 3 & 0,87892 & 7,2016 & 0,59549 & $-12,828$ \\
\hline & & & {$[0,6597]$} & {$[0,3026]$} & {$[0,9958]$} & \\
\hline \multirow[t]{4}{*}{ Veículos automotores } & d & 3 & 1,1231 & 6,9708 & 0,38909 & $-10,783$ \\
\hline & & & {$[0,3341]$} & {$[0,3236]$} & {$[1,0000]$} & \\
\hline & $d+1$ & 4 & 1,231 & 8,5128 & 0,55326 & $-10,517$ \\
\hline & & & {$[0,2356]$} & {$[0,2029]$} & {$[0,9978]$} & \\
\hline \multirow[t]{4}{*}{ Peças e outros veículos } & $\mathrm{d}$ & 1 & 1,2036 & 11,896 & 0,46166 & $-13,018$ \\
\hline & & & {$[0,2379]$} & {$[0,0643]$} & {$[0,9998]$} & \\
\hline & $d+1$ & 2 & 1,127 & 6,632 & 0,48765 & $-12,539$ \\
\hline & & & {$[0,3219]$} & {$[0,3562]$} & {$[0,9999]$} & \\
\hline \multirow[t]{4}{*}{ Madeira e mobiliário } & $\mathrm{d}$ & 3 & 1,4375 & 5,5227 & 1,0346 & $-12,940$ \\
\hline & & & {$[0,0945]$} & {$[0,4787]$} & {$[0,4407]$} & \\
\hline & $d+1$ & 4 & 1,9827 & 4,628 & 0,50213 & $-12,365$ \\
\hline & & & {$[0,0082]$} & {$[0,5923]$} & {$[0,9942]$} & \\
\hline \multirow[t]{4}{*}{ Celulose, papel e gráfica } & $\mathrm{d}$ & 2 & 1,2316 & 4,146 & 0,80478 & $-14,195$ \\
\hline & & & {$[0,2125]$} & {$[0,6569]$} & {$[0,8560]$} & \\
\hline & $d+1$ & 3 & 1,3488 & 6,058 & 0,6081 & $-13,613$ \\
\hline & & & {$[0,1330]$} & {$[0,4167]$} & {$[0,9952]$} & \\
\hline \multirow[t]{4}{*}{ Elementos químicos } & d & 3 & 1,3206 & 3,7113 & 0,4849 & $-14,106$ \\
\hline & & & {$[0,1584]$} & {$[0,7157]$} & {$[0,9998]$} & \\
\hline & $d+1$ & 4 & 1,1197 & 3,0236 & 0,13971 & $-13,811$ \\
\hline & & & {$[0,3418]$} & {$[0,8059]$} & {$[1,0000]$} & \\
\hline \multirow[t]{4}{*}{ Têxtil } & d & 3 & 1,2136 & 4,018 & 0,40268 & $-14,099$ \\
\hline & & & {$[0,2478]$} & {$[0,6742]$} & {$[0,9999]$} & \\
\hline & $d+1$ & 4 & 1,1556 & 4,4235 & 0,86644 & $-13,645$ \\
\hline & & & {$[0,2971]$} & {$[0,6196]$} & {$[0,7614]$} & \\
\hline \multirow[t]{4}{*}{ Calçados } & d & 1 & 1,2439 & 9,4045 & 0,62103 & $-14,188$ \\
\hline & & & {$[0,2006]$} & {$[0,1521]$} & {$[0,9856]$} & \\
\hline & $d+1$ & 2 & 1,0167 & 7,5547 & 0,67827 & $-13,782$ \\
\hline & & & {$[0,4613]$} & {$[0,2726]$} & {$[0,9780]$} & \\
\hline
\end{tabular}

Obs.: AR 1-4, normal e HET correspondem, respectivamente, às estatísticas dos testes para ausência de autocorrelação, normalidade e ausência de heterocedasticidade do vetor de erros. Os valores entre colchetes correspondem aos de probabilidade dos testes. 
Tabela A.4

Testes de diagnósticos: modelo VAR quantum $\mathrm{X}$ relativo de preços

\begin{tabular}{|c|c|c|c|c|c|c|}
\hline Setor & & $\mathrm{k}$ & AR1-4 & Normal & HET & BIC \\
\hline \multirow[t]{4}{*}{ Extrativa mineral } & $\mathrm{d}$ & 3 & 1,916 & 6,3708 & 0,48932 & $-15,414$ \\
\hline & & & {$[0,0093]$} & {$[0,3830]$} & {$[0,9998]$} & \\
\hline & $d+1$ & 4 & 1,7928 & 4,7874 & 0,17704 & $-14,885$ \\
\hline & & & {$[0,0203]$} & {$[0,5713]$} & {$[1,0000]$} & \\
\hline \multirow[t]{4}{*}{ Siderurgia } & d & 4 & 0,84884 & 3,9449 & 0,076568 & $-14,172$ \\
\hline & & & {$[0,6974]$} & {$[0,6841]$} & {$[1,0000]$} & \\
\hline & $d+1$ & 5 & 1,0628 & 3,1516 & 0,036085 & $-13,550$ \\
\hline & & & {$[0,4157]$} & {$[0,7896]$} & {$[1,0000]$} & \\
\hline \multirow[t]{4}{*}{ Metais não-ferrosos } & d & 3 & 1,9122 & 10,496 & 0,60044 & $-13,513$ \\
\hline & & & {$[0,0115]$} & {$[0,1053]$} & {$[0,9924]$} & \\
\hline & $d+1$ & 4 & 1,2347 & 6,3827 & 0,20161 & $-13,499$ \\
\hline & & & {$[0,2356]$} & {$[0,3817]$} & {$[1,0000]$} & \\
\hline \multirow[t]{4}{*}{ Máquinas e tratores } & d & 3 & 2,1026 & 2,6359 & 0,6268 & $-12,904$ \\
\hline & & & {$[0,0038]$} & {$[0,8530]$} & {$[0,9894]$} & \\
\hline & $d+1$ & 4 & 2,1928 & 6,762 & 0,3007 & $-12,678$ \\
\hline & & & {$[0,0032]$} & {$[0,3434]$} & {$[1,0000]$} & \\
\hline \multirow[t]{4}{*}{ Material elétrico } & d & 3 & 1,2552 & 9,3238 & 0,42167 & $-14,177$ \\
\hline & & & {$[0,2190]$} & {$[0,1562]$} & {$[0,9999]$} & \\
\hline & $d+1$ & 4 & 1,2108 & 9,258 & 0,065066 & $-13,674$ \\
\hline & & & {$[0,2654]$} & {$[0,1596]$} & {$[1,0000]$} & \\
\hline \multirow[t]{4}{*}{ Equipamentos eletrônicos } & d & 2 & 0,86652 & 11,139 & 0,97003 & $-13,377$ \\
\hline & & & {$[0,6789]$} & {$[0,0842]$} & {$[0,5553]$} & \\
\hline & $d+1$ & 3 & 0,87892 & 7,2016 & 0,59549 & $-12,828$ \\
\hline & & & {$[0,6597]$} & {$[0,3026]$} & {$[0,9958]$} & \\
\hline \multirow[t]{4}{*}{ Veículos automotores } & d & 3 & 1,1231 & 6,9708 & 0,38909 & $-10,783$ \\
\hline & & & {$[0,3341]$} & {$[0,3236]$} & {$[1,0000]$} & \\
\hline & $d+1$ & 4 & 1,231 & 8,5128 & 0,55326 & $-10,517$ \\
\hline & & & {$[0,2356]$} & {$[0,2029]$} & {$[0,9978]$} & \\
\hline \multirow[t]{4}{*}{ Peças e outros veículos } & d & 1 & 1,2036 & 11,896 & 0,46166 & $-13,018$ \\
\hline & & & {$[0,2379]$} & {$[0,0643]$} & {$[0,9998]$} & \\
\hline & $d+1$ & 2 & 1,127 & 6,632 & 0,48765 & $-12,539$ \\
\hline & & & {$[0,3219]$} & {$[0,3562]$} & {$[0,9999]$} & \\
\hline \multirow[t]{4}{*}{ Madeira e mobiliário } & d & 3 & 1,4375 & 5,5227 & 1,0346 & $-12,940$ \\
\hline & & & {$[0,0945]$} & {$[0,4787]$} & {$[0,4407]$} & \\
\hline & $d+1$ & 4 & 1,9827 & 4,628 & 0,50213 & $-12,365$ \\
\hline & & & {$[0,0082]$} & {$[0,5923]$} & {$[0,9942]$} & \\
\hline \multirow[t]{4}{*}{ Celulose, papel e gráfica } & d & 2 & 1,2316 & 4,146 & 0,80478 & $-14,195$ \\
\hline & & & {$[0,2125]$} & {$[0,6569]$} & {$[0,8560]$} & \\
\hline & $d+1$ & 3 & 1,3488 & 6,058 & 0,6081 & $-13,613$ \\
\hline & & & {$[0,1330]$} & {$[0,4167]$} & {$[0,9952]$} & \\
\hline \multirow[t]{4}{*}{ Elementos químicos } & d & 3 & 1,3206 & 3,7113 & 0,4849 & $-14,106$ \\
\hline & & & {$[0,1584]$} & {$[0,7157]$} & {$[0,9998]$} & \\
\hline & $d+1$ & 4 & 1,1197 & 3,0236 & 0,13971 & $-13,811$ \\
\hline & & & {$[0,3418]$} & {$[0,8059]$} & {$[1,0000]$} & \\
\hline \multirow[t]{4}{*}{ Têxtil } & d & 3 & 1,2136 & 4,018 & 0,40268 & $-14,099$ \\
\hline & & & {$[0,2478]$} & {$[0,6742]$} & {$[0,9999]$} & \\
\hline & $d+1$ & 4 & 1,1556 & 4,4235 & 0,86644 & $-13,645$ \\
\hline & & & {$[0,2971]$} & {$[0,6196]$} & {$[0,7614]$} & \\
\hline \multirow[t]{4}{*}{ Calçados } & d & 1 & 1,2439 & 9,4045 & 0,62103 & $-14,188$ \\
\hline & & & {$[0,2006]$} & {$[0,1521]$} & {$[0,9856]$} & \\
\hline & $d+1$ & 2 & 1,0167 & 7,5547 & 0,67827 & $-13,782$ \\
\hline & & & {$[0,4613]$} & {$[0,2726]$} & {$[0,9780]$} & \\
\hline
\end{tabular}

Obs.: AR 1-4, normal e HET correspondem, respectivamente, às estatísticas dos testes para ausência de autocorrelação, normalidade e ausência de heterocedasticidade do vetor de erros. Os valores entre colchetes correspondem aos de probabilidade dos testes. 